Original Research

\title{
Incorporation of heparin/BMP2 complex on GOCS-modified magnesium alloy to synergistically improve corrosion resistance, anticoagulation, and osteogenesis
}

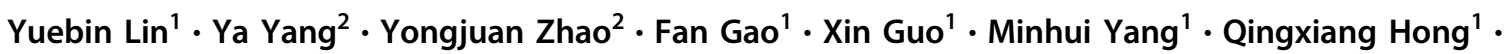 \\ Zhongmei Yang ${ }^{1} \cdot$ Juan Dai ${ }^{1} \cdot$ Changjiang Pan ${ }^{1}$
}

Received: 27 September 2020 / Accepted: 15 February 2021 / Published online: 6 March 2021

(c) The Author(s) 2021

\begin{abstract}
The in vivo fast degradation and poor biocompatibility are two major challenges of the magnesium alloys in the field of artificial bone materials. In this study, graphene oxide (GO) was first functionalized by chitosan (GOCS) and then immobilized on the magnesium alloy surface, finally the complex of heparin and bone morphogenetic protein 2 was incorporated on the modified surface to synergistically improve the corrosion resistance, anticoagulation, and osteogenesis. Apart from an excellent hydrophilicity after the surface modification, a sustained heparin and BMP2 release over 14 days was achieved. The corrosion resistance of the modified magnesium alloy was significantly better than that of the control according to the results of electrochemical tests. Moreover, the corrosion rate was also significantly reduced in contrast to the control. The modified magnesium alloy not only had excellent anticoagulation, but also can significantly promote osteoblast adhesion and proliferation, upregulate the expression of alkaline phosphatase and osteocalcin, and enhance mineralization. Therefore, the method of the present study can be used to simultaneously improve the corrosion resistance and biocompatibility of the magnesium alloys targeted for the orthopedic applications.
\end{abstract}

\section{Graphical Abstract}

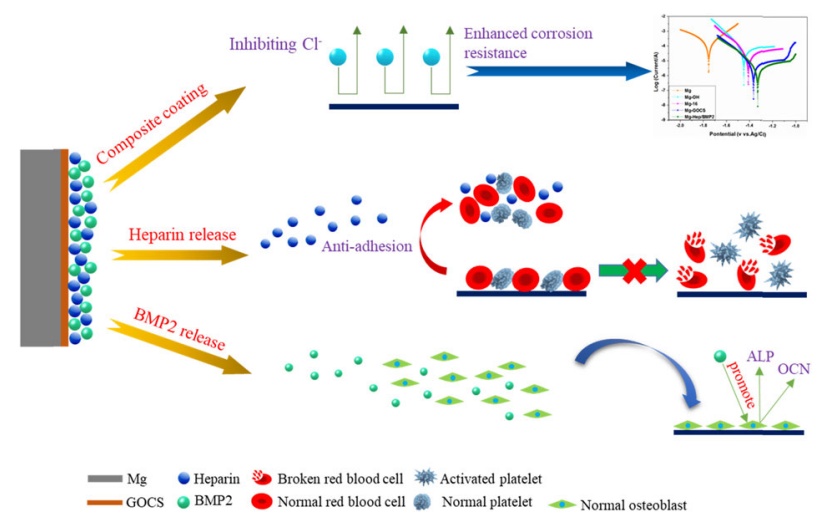

These authors contributed equally: Yuebin Lin, Ya Yang

Changjiang Pan

panchangjiang@hyit.edu.cn

1 Faculty of Mechanical and Material Engineering, Huaiyin Institute of Technology, Huai'an 223003, China

2 The Affiliated Huai' an Hospital of Xuzhou Medical University, Huai' an 223003, China 


\section{Highlights}

- The GOCS@Hep/BMP2 bioactive coating was created on the magnesium surface.

- The coated magnesium alloy had good wettability and corrosion resistance.

- The coating can improve anticoagulation and osteogenesis of magnesium alloy.

\section{Introduction}

The tendency toward the biodegradable implant is attracting more and more attention due to the increase of orthopedic traumas $[1,2]$. In this aspect, magnesium and its alloys have been considered the ideal candidate as a permissible implant material to support the structure temporarily, and safely degrade in a body [3]. First, the density and mechanical properties of the magnesium alloy are close to human bone so that it can effectively avoid the stress shielding effect when used as a bone implant material [4]. Second, magnesium can be degraded in the physiological environments in the form of $\mathrm{Mg}^{2+}$, and the degradation products can be excreted out of the body or absorbed by the human body. Consequently, as a promising biodegradable metal, it can not only avoid being removed by the second operation, but also reduce the risk of physical pain of patients and reinfection [5].

Although magnesium alloy has no obvious toxicity to human body and can even promote the healing of bone tissue in some cases [6-8], its rapid degradation in the physiological conditions usually exceeds the threshold that the human physiological environment can withstand. A large number of hydrogen gas and magnesium ions, as well as rapidly rising $\mathrm{pH}$ value, can not only destroy the mechanical integrity of the loading-bearing implant, but also break the in vivo physiological balance, leading to serious inflammatory and toxic reactions at the interface between the implant and human tissues, finally resulting in the implantation failure. These key problems regarding the application and safety of the magnesium alloy must be mitigated by the effective strategies before the application.

Surface modification represents one of the key and effective methods to enhance the corrosion resistance and biocompatibility because the corrosion behaviors and biocompatibility of the magnesium alloys are closely related to their surface properties [9]. At present, many surface modification methods have been employed to control the surface anticorrosion and bioactivities of the magnesium alloys [10-12]. By forming a chemical conversion layer or coating on the magnesium surface to isolate the matrix from the corrosive environment, the corrosion resistance can be significantly improved, which could reduce a series of adverse physiological reactions caused by the rapid degradation, and thus improve the biocompatibility to a certain extent. However, these methods have limited improvement on the surface properties and functions of the magnesium alloys because of the thinner surface-modified layer, small number of biomolecules, and easy deactivation of bioactive substances. Although the polymer or Ca-P coating on the magnesium alloy surface has been extensively investigated and they can significantly improve the corrosion resistance, both bioactivities and corrosion resistance in the in vivo environments are inferior to the clinic requirements. On the other side, studies have shown that the poor anticoagulation of the bone implant would induce platelet adhesion and activation, resulting in thrombus and poor blood flow at the implantation site, even local tissue necrosis [13]. Therefore, magnesium alloys used for the bone implant materials not only need to control their degradation behavior in vivo, but also should be endowed with good osteogenic and anticoagulant properties.

Graphene oxide (GO), a 2D carbon nanomaterial, has been widely investigated in the field of biomaterials and tissue engineering because of its huge specific surface area, high mechanical strength, and good biocompatibility $[14,15]$. GO has rich carboxyl groups showing negativecharged characteristic in electrolyte solution, which can prevent the adsorption of anions and thus improve the corrosion resistance and the biocompatibility of the magnesium alloys [16-18]. At the same time, the aromatic ring structure of GO can enhance the extracellular matrix (ECM) protein adsorption through non-covalent interaction, which can improve cell proliferation and differentiation [19, 20]. In addition, the rich hydroxyl, carboxyl, and epoxy groups of GO can be linked with other bioactive substances to achieve multi-functionalization. Moreover, its huge specific surface area also provides an excellent platform for loading bioactive molecules and drugs to enhance the bioactivities [21]. Chitosan has many bioactivities including good biocompatibility and antibacterial activity, and it is widely used in the biomaterials and tissue engineering. Consequently, the bioactivities of GO can be further improved by chitosan. Chitosan has also been demonstrated as the ability to enhance corrosion of the magnesium alloy [22]. Therefore, the immobilization of chitosan-functionalized GO (GOCS) on the magnesium alloy surface can not only improve the corrosion resistance and biocompatibility, but also provide an excellent platform for loading bioactive substances.

Heparin has been extensively used for the surface modification of biomaterials to improve the blood compatibility. Heparin has excellent binding affinities to various factors, such as vascular endothelial growth factor (VEGF) and BMP2 [23], and its strong negative-charged characteristics 
endow its good abilities to bind with the positively charged biomolecules [24]. BMP2 can promote osteoblast proliferation and differentiation [25, 26]. Meanwhile, BMP2 can bind to heparin due to its positively charged characteristic. Therefore, due to the positive-charged characteristic and huge specific area of GOCS, the complex of heparin and BMP2 can be further loaded on the surface of GOCS-modified magnesium alloy to improve the blood compatibility and promote osteoblast growth through the sustained release of heparin and BMP2.

In view of the bioactivities of GO, chitosan, heparin, and BMP2, a strategy for the surface modification of the magnesium alloy is proposed in the present study. First, GOCS was covalently immobilized on the magnesium alloy surface, which was modified by self-assembly of 16phosphonyl-hexadecanoic acid. Subsequently, the complex of heparin and BMP2 was loaded on the modified surface to enhance the anticoagulation and osteogenesis through the sustained release of heparin and BMP2. The advantage of this method is that a multifunctional surface can be achieved, which can not only improve the corrosion resistance of the magnesium alloy, but also improve its blood compatibility and osteogenesis.

\section{Materials and methods}

\subsection{Incorporation of heparin/BMP2 on GOCS- modified magnesium alloy surface}

$1 \mathrm{mg} / \mathrm{mL}$ GO suspension (XFNANO Materials Tech Co., Ltd, Nanjing, China) and $5 \mathrm{mg} / \mathrm{mL}$ chitosan $(0.2 \%$ acetic acid, $\mathrm{pH}$ 5.0) solution were thoroughly mixed $12 \mathrm{~h}$ with a ratio of 1:5 (volume ratio), and then $10 \mathrm{mM} 1$-(3-dimethylaminopropyl)-3-ethylcarbodiimide/N-hydroxysuccinimide (EDC/NHS, volume ratio 3:1) was added under stirring at $800 \mathrm{rpm}$. After $12 \mathrm{~h}$ reaction at room temperature, the mixture solution was transferred into a dialysis bag (MW:3500) to dialyze 5 days in deionized water, the remaining solution was finally centrifuged and dried to obtain GOCS.

AZ31B magnesium alloy plates were polished by $\mathrm{SiC}$ paper up to 2000 grits. After cleaning and drying, the plates were immersed in $3 \mathrm{M} \mathrm{NaOH}$ solution for $24 \mathrm{~h}$ at $75^{\circ} \mathrm{C}$, and the obtained samples were recorded as $\mathrm{Mg}-\mathrm{OH}$. $\mathrm{Mg}-\mathrm{OH}$ was immersed in $5 \mathrm{mM}$ 16-phosphonyl-hexadecanoic acid solution (in anhydrous ethanol) for $24 \mathrm{~h}$, then taken out and treated at $120^{\circ} \mathrm{C}$ for $12 \mathrm{~h}$, the sample was recorded as $\mathrm{Mg}$ 16. Mg-16 was activated in EDC/NHS (10 mM) for $1 \mathrm{~h}$, then reacted with GOCS solution $(6 \mathrm{mg} / \mathrm{mL})$ for $2 \mathrm{~h}$ to obtain GOCS-modified sample (Mg-GOCS). Finally, $2 \mathrm{mg} /$ $\mathrm{mL}$ heparin solution and $100 \mathrm{ng} / \mathrm{mL}$ BMP2 solution were fully mixed by $1: 1$ (vol\%), and then dropped and fully covered on Mg-GOCS surface for adsorbing $6 \mathrm{~h}$ to obtain the final sample (Mg-Hep/BMP2).

\subsection{Surface characterization}

Attenuated total reflection Fourier transform infrared spectroscopy (ATR-FTIR, TENSOR27, Bruker of Germany) was utilized to examine the surface chemical groups. The scanning range was $4000-650 \mathrm{~cm}^{-1}$. $\mathrm{Mg}$ and $\mathrm{Mg}-\mathrm{Hep} / \mathrm{BMP} 2$ were analyzed by Raman spectroscopy (Renishaw, UK, RM 2000) to investigate the GO structure on the surface. The surface morphologies and element composition were investigated by scanning electron microscopy (SEM, FEI Quata 250, USA) and X-ray energy dispersive spectroscopy (EDS, IMA X-Max 20, Britain), respectively. The water contact angle was measured by a DSA25 contact angle meter (Krüss GmbH, Germany) in order to characterize the surface hydrophilicity. Three parallel samples were measured and the values were expressed as mean \pm standard deviation.

\subsection{Release profiles of heparin and BMP2}

The Mg-Hep/BMP2 sample was immersed in $2 \mathrm{~mL}$ Hanks simulated body fluid (SBF) solution. At each predetermined time, $100 \mu \mathrm{L}$ solution was taken out and the medium was supplemented with $100 \mu \mathrm{l}$ fresh SBF. The release amount of BMP2 was measured by BMP2 enzyme-linked immunosorbent assay (ELISA) kit [27]. Briefly, $100 \mu \mathrm{L}$ standard solution and $100 \mu \mathrm{L}$ sample solution were, respectively, added into the test plate. After cultivated $90 \mathrm{~min}$ at $37^{\circ} \mathrm{C}$, $100 \mu \mathrm{L}$ of Biotinylated anti-mouse BMP2 antibody was added to incubate $60 \mathrm{~min}$, followed by addition of $100 \mu \mathrm{L}$ Avidin-Biotin-Peroxidase Complex solution. Finally, $90 \mu \mathrm{L}$ chromogenic agent was added to incubate $20 \mathrm{~min}$, and the terminating solution was finally added to stop the reaction. The absorbance at $450 \mathrm{~nm}$ was measured and the concentration of BMP2 was calculated according to the standard curve.

The concentration of heparin was measured by azure A staining method described in our previous work [28]. In brief, $100 \mu \mathrm{L}$ of the sample solution was added to the 96well culture plate, and then $100 \mu \mathrm{L}$ of azure A solution was added. Subsequently, the absorbance at $505 \mathrm{~nm}$ was measured. The heparin concentration was calculated based on the standard curve and the release curve was plotted.

\subsection{Electrochemical and biodegradable behaviors}

\subsubsection{Potentiodynamic polarization curves and electrochemical impedance spectroscopy (EIS)}

The potentiodynamic polarization curves and EIS of the different samples were measured on a CHI660D electrochemical 
workstation using the standard three-electrode system including a Pt plate as the auxiliary electrode, an $\mathrm{Ag} / \mathrm{AgCl}$ electrode with $3 \mathrm{M} \mathrm{KCl}$ as the reference electrode, and the sample as the working electrode. The test was conducted in Hanks SBF. The sample was sealed with silicone rubber with copper wire as the conductor. The exposed area was about $1 \mathrm{~cm}^{2}$. Before testing, the sample was soaked in SBF until the open circuit potential was stable. The scanning speed was $1 \mathrm{mV} / \mathrm{s}$. The corrosion current density was fitted by Tafel extrapolation method, and the annual corrosion depth was calculated according to the following formula [29]:

$d=3.28 \times 10^{-3}(M / n \rho) I_{\text {corr }}$

where $d$ represents annual corrosion depth (mm/year), $M$ is the molar mass of $\mathrm{Mg}(24 \mathrm{~g} / \mathrm{mol}), n$ is the valence of $\mathrm{Mg}(n=$ 2), $\rho$ is the density of magnesium $\left(1.74 \mathrm{~g} / \mathrm{cm}^{3}\right)$, and $I_{\text {corr }}$ is the corrosion current density $\left(\mu \mathrm{A} / \mathrm{cm}^{2}\right)$.

The EIS was also done on the Chi660D electrochemical workstation by scanning from $10^{5}$ to $0.1 \mathrm{~Hz}$ at open circuit potential with a sinusoidal alternating current amplitude of $10 \mathrm{mV}$.

\subsection{2 $\mathrm{pH}$ changes and $\mathrm{Mg}^{2+}$ release}

The magnesium alloy sealed with silicone rubber was immersed in $20 \mathrm{~mL}$ SBF solution, and the medium was refreshed every 2 days. The $\mathrm{pH}$ value of $\mathrm{SBF}$ was measured by $\mathrm{pH}$ meter at the predetermined time (1-7, 10, and 14 days), three parallel samples were measured and then the values were averaged.

For $\mathrm{Mg}^{2+}$ release, the sealed sample was immersed in $5 \mathrm{~mL}$ SBF solution, and then $200 \mu \mathrm{L}$ solution was taken out at the different times (1-7, 10, and 14 days) and supplemented with $200 \mu \mathrm{L}$ fresh SBF. The $\mathrm{Mg}^{2+}$ release concentration was measured by inductively coupled plasma atomic emission spectrometer (ICP-AES, Optima 7000 DV). Three parallel samples were measured and then the average value was calculated.

\subsection{Anticoagulation}

\subsubsection{Platelet adhesion}

The anticoagulant whole blood of a healthy volunteer was centrifuged $15 \mathrm{~min}$ at $1500 \mathrm{r} / \mathrm{min}$ to obtain platelet-rich plasma (PRP). $200 \mu \mathrm{L}$ PRP was fully covered on the surface to incubate $2 \mathrm{~h}$ at $37^{\circ} \mathrm{C}$. After washing with PBS, the attached platelets were fixed by $2.5 \%$ glutaraldehyde solution at $4{ }^{\circ} \mathrm{C}$. The sample was successively dehydrated with 50, 70, 90, 100\% ethanol solutions. After dried and sputtered a gold layer, the platelets were observed by SEM (FEI
Quata 250, USA). Ten SEM images with small magnifications $(\times 500)$ were randomly selected to count the platelets, and the values were averaged and expressed as platelets per unit area.

\subsection{2 cGMP assay}

The cGMP was measured by ELISA to characterize the platelet activation [30]. The samples were incubated with PRP for $1 \mathrm{~h}$ at $37^{\circ} \mathrm{C}$, and then $100 \mu \mathrm{L}$ Triton-X was introduced. After sonication, the mixture was centrifuged at $3000 \mathrm{rpm}$, and the supernatant was analyzed according to the instruction of the cGMP ELISA kit.

\subsubsection{Hemolysis}

The red blood cells were obtained by centrifuging the anticoagulant whole blood of a healthy volunteer. The hemolysis rate was obtained according to our previous method [31]. The normal saline was used to prepare $2 \%$ red blood cell suspension. $2 \mathrm{~mL}$ suspension was incubated $3 \mathrm{~h}$ with the sample at $37^{\circ} \mathrm{C}$. Subsequently, $1 \mathrm{~mL}$ solution was taken out and centrifuged $5 \mathrm{~min}$ at $3000 \mathrm{r} / \mathrm{min}, 200 \mu \mathrm{L}$ supernatant was used to measure the absorbance at $450 \mathrm{~nm}$ by a micro-plate reader (Bio-Tek, Eons). The $2 \%$ red blood cell solution by normal saline was used as the negative control, and the $2 \%$ red blood cell by the distilled water was used as the positive control. The following formula is used for calculating the hemolysis rate:

Hemolysis $(\%)=\left(A_{\text {sample }}-A_{\text {negative }}\right) /\left(A_{\text {positive }}-A_{\text {negative }}\right) \times 100 \%$

where $A_{\text {sample }}$ represents the OD value of sample, $A_{\text {negative }}$ and $A_{\text {positive }}$ are the OD values of negative control and positive control, respectively.

\subsection{Osteoblast behaviors}

\subsubsection{Cell adhesion}

The samples were sterilized by ultraviolet for $12 \mathrm{~h}$, and then $0.5 \mathrm{~mL}$ osteoblast (MC3T3-E1, Nanjing Cobioer BioTechnology Co., Ltd) suspension (passage 4, $5 \times 10^{4}$ cells/ $\mathrm{mL}$ ) and $1.5 \mathrm{~mL}$ culture medium were added for culturing for 1 and 3 days at $37^{\circ} \mathrm{C}$ in a humidified incubator with $5 \%$ $\mathrm{CO}_{2}$, respectively. After washing with PBS, the cells were fixed by $2.5 \%$ glutaraldehyde at $4{ }^{\circ} \mathrm{C}$. The attached cells were successively stained by rhodamine and 4, 6diamidino-2-phenylindole (Sigma-Aldrich, Shanghai), and finally the cells were observed by a fluorescent microscopy (Carl Zeiss, Inverted A2 Imager). 
Fig. 1 a ATR-FTIR curves of the different samples, the measurements were performed at room temperature with the scanning scope of $4000-650 \mathrm{~cm}^{-1}$; b Raman spectra of $\mathrm{Mg}$ and $\mathrm{Mg}-\mathrm{Hep} / \mathrm{BMP}$, the sharp and clear $\mathrm{G}$ and $\mathrm{D}$ peaks of GO were observed on Mg-Hep/BMP2
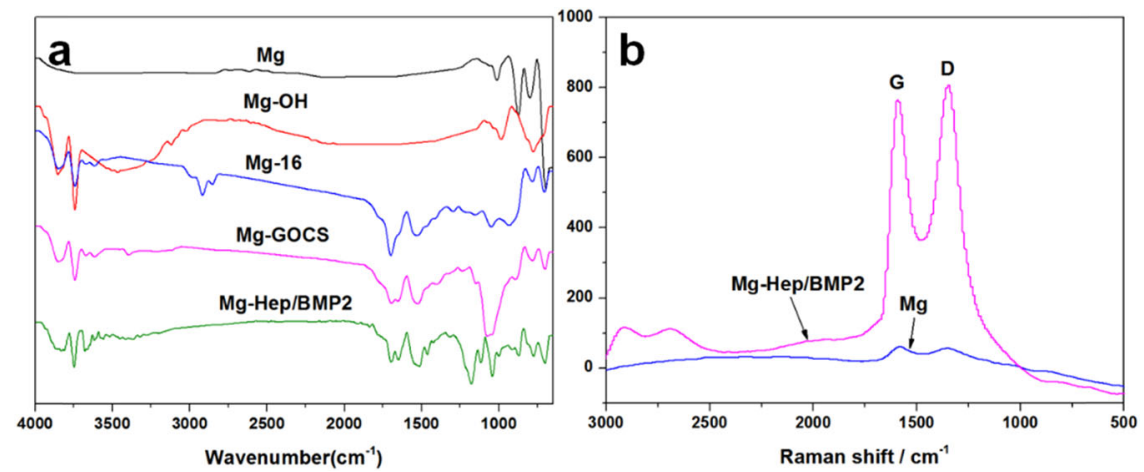

\subsubsection{Cell counting kit-8 (CCK-8) assay}

The osteoblasts were seeded on the sample surface and cultured as mentioned above. After culturing for 1 and 3 days, respectively, the sample was transferred into a new culture plate and then $0.5 \mathrm{ml}$ of $10 \%$ CCK- 8 solution was added for culturing for $3.5 \mathrm{~h}$. Finally, $100 \mu \mathrm{L}$ medium was taken out to measure the absorbance at $450 \mathrm{~nm}$. Three parallel samples were measured and the values were averaged.

\subsubsection{Alkaline phosphatase (ALP) and osteocalcin (OCN) expression}

ALP and OCN expression of osteoblasts was evaluated by ELISA. First, $0.5 \mathrm{ml}$ osteoblasts with a concentration of $5 \times$ $10^{4}$ cells $/ \mathrm{ml}$ were inoculated on the sample surface for 1 and 3 days, respectively. The supernatant was analyzed according to the instruction of the ALP and OCN ELISA kit. The concentrations of ALP and OCN were calculated according to the standard curve.

\subsubsection{Mineralization}

The osteoblast mineralization was determined by Alizarin red S staining method described elsewhere [32]. First, the cells were seeded on the sample surface for culturing for 7 and 21 days, respectively. The attached cells were fixed by $2.5 \%$ glutaraldehyde solution for $30 \mathrm{~min}$. After cleaning, $40 \mathrm{mM}$ Alizarin red $\mathrm{S}$ ( $\mathrm{pH} 4.1$ ) solution was added on the surface for incubating $30 \mathrm{~min}$. The cells were scraped off the surface with a cell scraper and transferred to $10 \%$ acetic acid solution, then the solution was heated at $85^{\circ} \mathrm{C}$ for $10 \mathrm{~min}$ and centrifuged. Finally, the supernatant was neutralized with $10 \%$ ammonia hydroxide, and the absorbance was measured at $405 \mathrm{~nm}$.

\subsection{Statistical analysis}

SPSS software was used to analyzed the results of water contact angle, anticoagulation (including platelet number, platelet activation, and hemolysis rate), osteoblast proliferation (CCK-8), and function (ALP, OCN, and mineralization) using one-way ANOVA, and $p<0.05$ is considered to be statistically significant. All tests were done three times with three parallel samples.

\section{Results and discussion}

\subsection{Sample characterization}

The ATR-FTIR curves of the different samples are shown in Fig. 1a. No obvious infrared absorption can be detected on $\mathrm{Mg}$ surface, indicating that the pristine $\mathrm{Mg}$ surface had no chemical groups. In contrast, an obvious infrared absorption peak at $3700 \mathrm{~cm}^{-1}$ can be detected on $\mathrm{Mg}-\mathrm{OH}$, which was associated with the infrared absorption of hydroxyl stretching vibration of $\mathrm{Mg}(\mathrm{OH})_{2}$ [33], demonstrating that alkali heat treatment can produce a large number of hydroxyl groups in the form of $\mathrm{Mg}(\mathrm{OH})_{2}$ on the magnesium surface. The 16-phosphonyl-hexadecanoic acid can be further immobilized on $\mathrm{Mg}-\mathrm{OH}$ surface by the dehydration reaction between phosphonyl and hydroxyl. Therefore, after the immobilization of 16-phosphonylhexadecanoic acid, the infrared absorption peaks of methyl and methylene can be observed at 2850 and $2920 \mathrm{~cm}^{-1}$, respectively, and the $\mathrm{C}=\mathrm{O}$ infrared absorption of carboxyl also appeared at $1720 \mathrm{~cm}^{-1}$, indicating that 16phosphonyl-hexadecanoic acid was successfully introduced on the surface. The surface carboxyl group can covalently react with the amine group of GOCS in the form of amide so that GOCS can be grafted on the surface. Therefore, after the immobilization of GOCS, the infrared absorption of carbonyl group in amide group can be detected at $1680 \mathrm{~cm}^{-1}$, concurrently the bending vibration absorption of $\mathrm{N}-\mathrm{H}$ and $\mathrm{C}-\mathrm{N}$ can be found at 1530 and $1400 \mathrm{~cm}^{-1}$, respectively. The strong and sharp peak at $1100 \mathrm{~cm}^{-1}$ on Mg-GOCS can be attributed to the adsorption of $\mathrm{C}-\mathrm{O}$. Heparin and bone morphogenetic protein 2 (Hep/BMP2) displayed negativecharged characteristic. After loading on the positively 
Fig. 2 Representative SEM images elucidating the morphologies of $\mathrm{Mg}$ (a), $\mathrm{Mg}$ $\mathrm{OH}$ (b), Mg-16 (c), Mg-GOCS (d), and Mg-Hep/BMP2 (e)

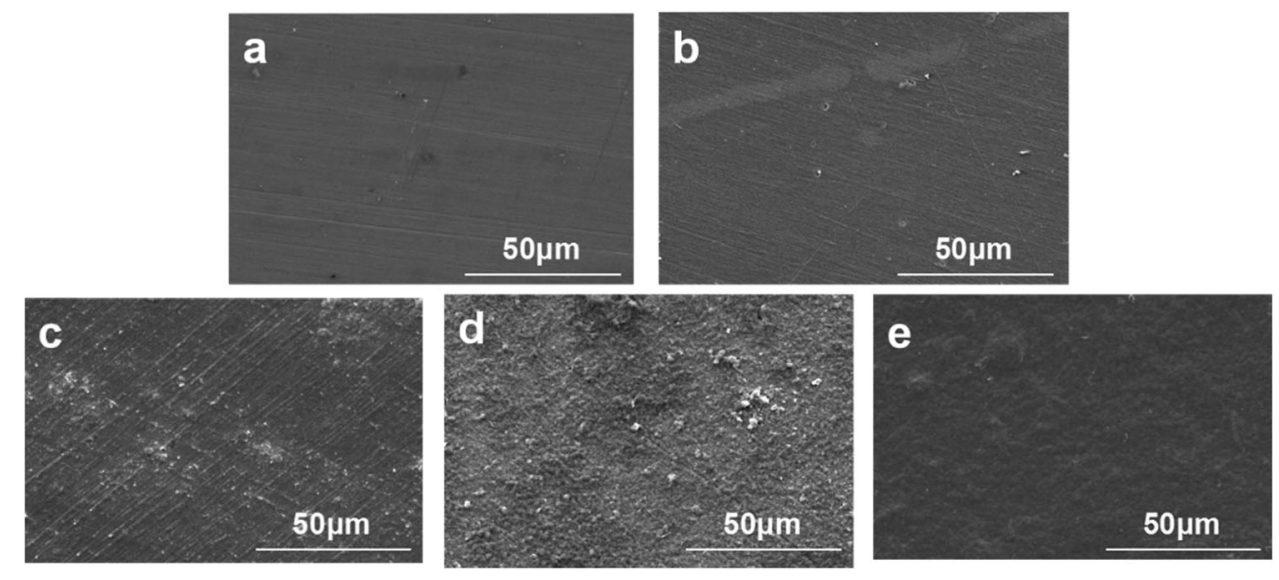

Table 1 Elemental compositions of the different surfaces characterized by EDS

\begin{tabular}{lccccccccc}
\hline Samples & \multicolumn{10}{l}{ Atomic concentration (at. \%) } \\
\cline { 2 - 9 } & $\mathrm{Mg}$ & $\mathrm{O}$ & $\mathrm{Al}$ & $\mathrm{C}$ & $\mathrm{P}$ & $\mathrm{N}$ & $\mathrm{S}$ & $\mathrm{Na}$ \\
\hline $\mathrm{Mg}$ & 87.5 & 9.9 & 2.6 & - & - & - & - & - \\
$\mathrm{Mg}-\mathrm{OH}$ & 78.8 & 20.2 & 1.0 & - & - & - & - & - \\
$\mathrm{Mg}-16$ & 54.3 & 23.34 & - & 21.79 & 0.57 & - & - & - \\
Mg-GOCS & 23.36 & 34.24 & - & 35.29 & - & 7.11 & - & - \\
Mg-Hep/BMP2 & 2.74 & 38.22 & - & 41.47 & - & 9.48 & 7.29 & 0.80 \\
\hline
\end{tabular}

charged GOCS-modified surface, the peaks at 1210 and $780 \mathrm{~cm}^{-1}$ on $\mathrm{Mg}-\mathrm{Hep} / \mathrm{BMP} 2$ can be attributed to $\mathrm{S}=\mathrm{O}$ and $\mathrm{S}-\mathrm{O}$ stretching vibrations, respectively, which indicated the successful introduction of heparin. Due to the electrostatic interaction between GOCS and heparin, the $\mathrm{C}-\mathrm{O}$ peak shifted from 1100 to $1035 \mathrm{~cm}^{-1}$ [34]. The peak at $1700 \mathrm{~cm}$ ${ }^{-1}$ belonged to the vibrational absorption of carbonyl group. In order to further investigate the surface chemical structure, the Raman spectra of $\mathrm{Mg}$ and $\mathrm{Mg}-\mathrm{Hep} / \mathrm{BMP} 2$ were measured, and the results are shown in Fig. 1b. It can be seen that there was no obvious Raman absorption on Mg surface. Two sharp peaks at 1590 and $1350 \mathrm{~cm}^{-1}$ on $\mathrm{Mg}-\mathrm{Hep} / \mathrm{BMP} 2$ can be attributed to the G peak and D peak of GO [35], indicating that GO has been successfully introduced on the magnesium surface.

The surface morphologies and element compositions of the pristine and modified magnesium alloys were further characterized by SEM and EDS, respectively, and the results are shown in Fig. 2 and Table 1. No special morphologies on $\mathrm{Mg}$ surface were observed besides a few scratches caused by polishing, and the surface elements were mainly composed of $\mathrm{Mg}$ and $\mathrm{O}$, indicating that the magnesium alloy can be oxidized in air. Alkali heat treatment can produce $\mathrm{Mg}(\mathrm{OH})_{2}$ layer on the surface, so the amount of $\mathrm{Mg}$ on the surface decreased concurrently with the increase of oxygen, however, there was no obvious difference for micro-morphologies between $\mathrm{Mg}$ and $\mathrm{Mg}-\mathrm{OH}$. The occurrence of $\mathrm{C}$ and $\mathrm{P}$ elements on $\mathrm{Mg}-16$ surface demonstrated that 16-phosphonyl-hexadecanoic acid was successfully immobilized on the magnesium alloy surface, which can form an organic molecular layer covering the surface to enhance the corrosion resistance to some degree. As shown in Fig. 2d, the immobilized GOCS showed a typical granular morphology of chitosan [36], and the coating was continuous and intact, which can provide the isolation layer to enhance the corrosion resistance [37]. The $\mathrm{C}$ content on Mg-GOCS surface increased to $35.29 \%$ due to the introduction of GO and chitosan, and the appearance of nitrogen mainly came from chitosan, indicating that GOCS was successfully immobilized on the magnesium alloy surface. After loading Hep/BMP2, 7.29\% S element can be detected, suggesting that heparin was successfully introduced. The granular structure of chitosan disappeared and a uniform and smooth coating can be observed, the content of $\mathrm{Mg}$ was also reduced to $2.74 \%$, indicating that the surface coating was thicker and can completely cover the magnesium alloy surface.

Human body contains a plenty of water, the biomaterials will be in contact with the in vivo environment after the implantation, and therefore the surface wettability plays an important role on the biocompatibility. In the present study, the surface wettability of the different magnesium alloys was characterized by water contact angle, and the results are shown in Fig. 3a. The water contact angle of the untreated magnesium alloy was $54^{\circ}$, and the value is close to the results shown in literature [38], displaying the relative hydrophobicity in contrast to other samples. As shown in ATR-FTIR, alkali heat treatment can introduce a large amount of hydroxyl groups on the surface, which can significantly contribute to enhancement of the hydrophilicity, therefore the water contact angle of $\mathrm{Mg}-\mathrm{OH}$ was reduced to $36^{\circ}$. Although the immobilization of 16-phosphonylhexadecanoic acid consumed the hydrophilic hydroxyl groups, another hydrophilic carboxyl groups can be introduced on the surface, therefore the water contact angle of $\mathrm{Mg}-16$ had little change in contrast to $\mathrm{Mg}-\mathrm{OH}$. Although 
Fig. 3 a Water contact angles of the different samples, the data are statistically significant $(p<$ 0.05 ) as compared to the blank magnesium; b heparin and $\mathrm{BMP} 2$ release profiles of $\mathrm{Mg}$ Hep/BMP2 for 14 days
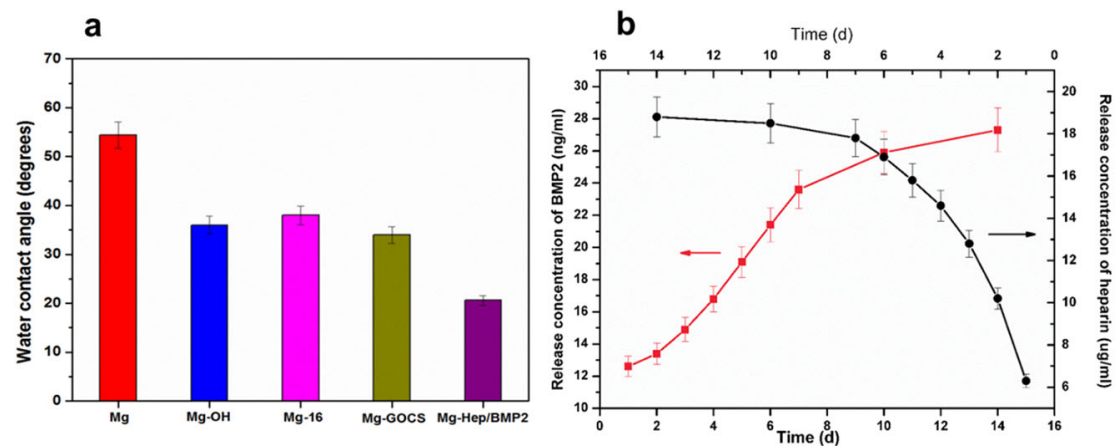

chitosan has better hydrophilicity, GO contains the aromatic hydrophobic structures, consequently, as compared to $\mathrm{Mg}$ and $\mathrm{Mg}-\mathrm{OH}$, the change of water contact angle was not obvious after GOCS was grafted onto magnesium alloy surface. The surface of heparin contains a lot of hydrophilic sulfonic and hydroxyl groups, therefore, the water contact angle decreased significantly after Hep/BMP2 was loaded on the surface.

GOCS with the positive charges can adsorb the negativecharged heparin/BMP2 complex, moreover, GO can be used to load heparin and BMP2 through non-covalent forces such as hydrophobic force and hydrogen bond. Its large specific surface area can effectively increase the loading amount of the bioactive substances. The release behaviors of BMP2 and heparin are shown in Fig. 3b. It can be seen that both BMP2 and heparin had an obvious burst release behavior of 1 day, and the concentration of BMP2 and heparin was $12.6 \mathrm{ng} / \mathrm{mL}$ and $6.3 \mu \mathrm{g} / \mathrm{mL}$, respectively. It was considered that the burst release was related to the low binding capacity of the bioactive substances existing on the outermost layer of the surface. From the 1st day to the 7th day, the release concentration increased almost linearly with the function of time, and the daily release concentration was $1.83 \mathrm{ng} / \mathrm{mL}$ (BMP2) and $1.92 \mu \mathrm{g} / \mathrm{mL}$ (heparin), respectively, which was significantly lower than that of the 1 st day. Although the release rate slowed down obviously, the release rate was stable. The release rate of BMP2 and heparin was further decreased from the 7th day to the 14th day, and the cumulative release concentrations of BMP2 and heparin at 14 days were $27.3 \mathrm{ng} / \mathrm{mL}$ and $18.8 \mu \mathrm{g} / \mathrm{mL}$, respectively, indicating that BMP2 and heparin release could release at least 14 days from the surface. The sustained release was beneficial to promote the differentiation and proliferation of osteoblasts and can endow the materials with good anticoagulant properties.

\subsection{Electrochemical and biodegradable behaviors}

The potentiodynamic polarization test is first done to evaluate the corrosion behaviors of the different samples, and the corrosion potential and corrosion current density were determined by Tafel method. The annual corrosion depth was calculated according to corrosion current density and Formula (1), and the results are shown in Fig. 4a and Table 2. In general, the more positive corrosion potential and the lower corrosion current indicate better corrosion resistance [39]. The corrosion potential of $\mathrm{Mg}(-1.758 \mathrm{~V})$ was the lowest among all samples, indicating that $\mathrm{Mg}$ had poor corrosion resistance. The corrosion current density and annual corrosion depth were $6.593 \times 10^{-5} \mathrm{~A} / \mathrm{cm}^{-2}$ and $1.49 \mathrm{~mm} /$ year, respectively, representing the fastest corrosion rate in contrast to other samples. The corrosion potential of $\mathrm{Mg}-\mathrm{OH}$ was positively shifted to $-1.449 \mathrm{~V}$, indicating that the corrosion resistance was improved due to the formation of $\mathrm{Mg}(\mathrm{OH})_{2}$ layer, therefore the corrosion current density and the annual corrosion depth of $\mathrm{Mg}-\mathrm{OH}$ were reduced to $2.567 \times 10^{-5} \mathrm{~A} / \mathrm{cm}^{-2}$ and $0.58 \mathrm{~mm} /$ year, respectively. However, $\operatorname{Mg}(\mathrm{OH})_{2}$ layer is not stable and can react with $\mathrm{Cl}^{-}$of the physiological environment to transform it into easily soluble $\mathrm{MgCl}_{2}$ [40]. In addition, although $\mathrm{Mg}-\mathrm{OH}$ sample had better hydrophilicity, it needed to be further modified because of the limited surface bioactivities. The self-assembly of 16-phosphonyl-hexadecanoic acid had the phosphating effect and covering effect on the surface, consequently, the corrosion potential of Mg-16 sample increased, while the corrosion current density and annual corrosion depth decreased to some degree. As shown in SEM images (Fig. 2), the immobilization of GOCS can form a dense layer on the magnesium alloy surface, which can effectively isolate the corrosion medium from the matrix, leading to the improvement of the corrosion resistance. At the same time, the corrosion of the magnesium alloy could lead to local alkalization due to the increase of $\mathrm{pH}$ value, but chitosan is not easy to dissolve in alkaline environment, which also contributed to improve the stability of GOCS coating, therefore the corrosion potential of Mg-GOCS increased obviously $(-1.366 \mathrm{~V})$, while corrosion current density $\left(7.682 \times 10^{-6} \mathrm{~A} / \mathrm{cm}^{-2}\right)$ and annual corrosion depth $(0.17 \mathrm{~mm} /$ year $)$ were further reduced. After loading Hep/BMP2 on Mg-GOCS, the corrosion potential slightly increased to $-1.328 \mathrm{~V}$, and the corrosion current density and annual corrosion depth decreased to $5.132 \times 10^{-6} \mathrm{~A} / \mathrm{cm}^{-2}$ 
Fig. 4 a Potentiodynamic polarization curves of the different samples; b Nyquist plots of the different samples; scatter: original values; line: calculative values; $b 1$ equivalent circuits of $\mathrm{Mg}, \mathrm{Mg}-\mathrm{OH}$ and $\mathrm{Mg}$ 16 ; b2 equivalent circuits of $\mathrm{Mg}$ GOCS and Mg-Hep/BMP2. c $\mathrm{pH}$ values and $\mathrm{Mg}^{2+}$ release profile (d) of the incubation medium solutions for the different samples which immersed in SBF for 7 days
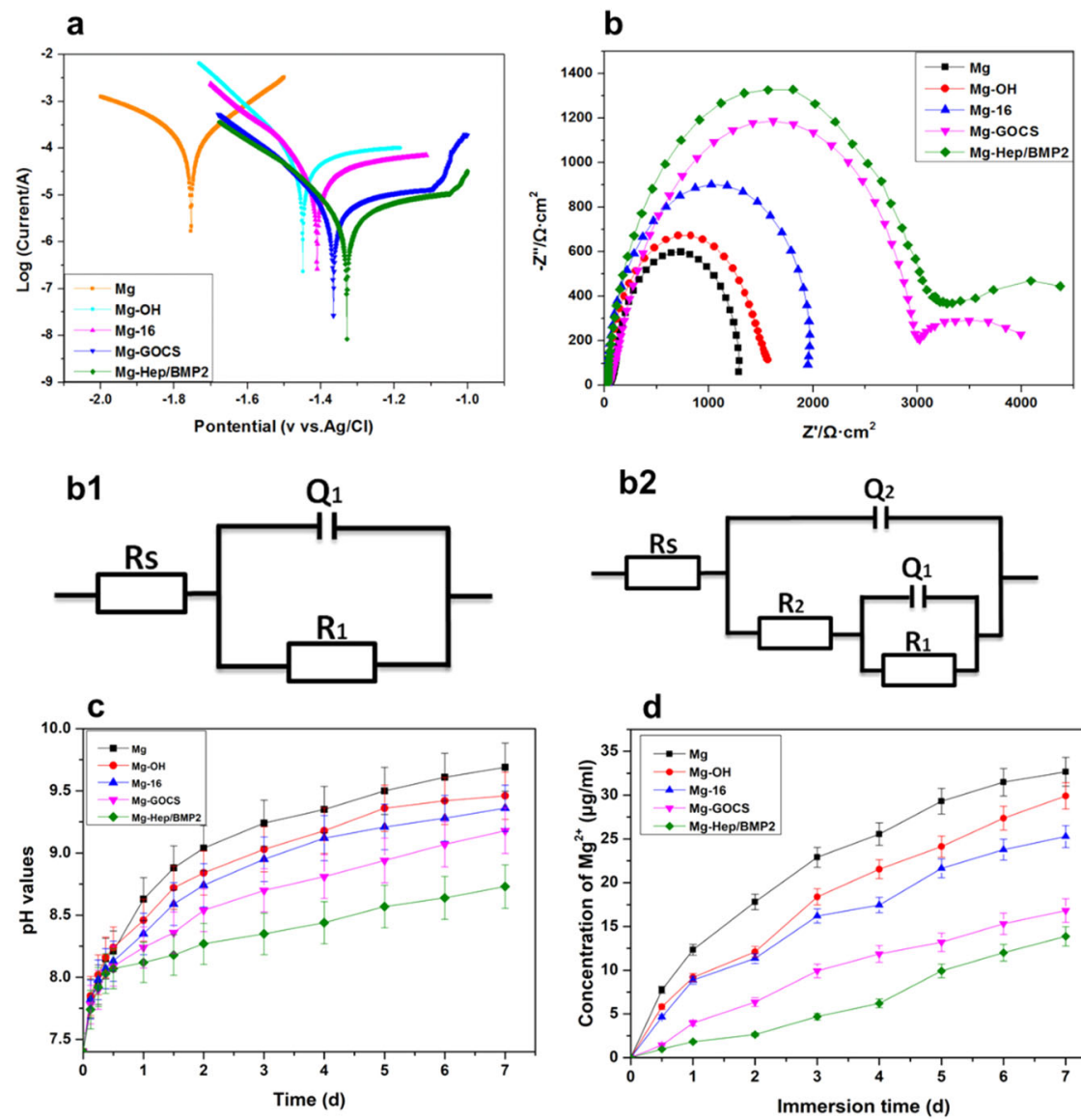

Table 2 Corrosion potential, corrosion current density, and annual corrosion depth of the different samples

\begin{tabular}{llll}
\hline Samples & $E_{\text {corr }} / V$ & $I_{\text {corr }} / A \mathrm{~cm}^{-2}$ & $\mathrm{~d} /(\mathrm{mm} / \mathrm{y})$ \\
\hline Mg & -1.758 & $6.593 \times 10^{-5}$ & 1.49 \\
Mg-OH & -1.449 & $2.567 \times 10^{-5}$ & 0.58 \\
Mg-16 & -1.410 & $9.856 \times 10^{-6}$ & 0.22 \\
Mg-GOCS & -1.366 & $7.682 \times 10^{-6}$ & 0.17 \\
Mg-Hep/BMP2 & -1.328 & $5.132 \times 10^{-6}$ & 0.12 \\
\hline
\end{tabular}

and $0.12 \mathrm{~mm} /$ year, respectively, indicating that the corrosion resistance was further improved. It may be due to the fact that the negative-charged heparin can prevent the adsorption of anions. At the same time, it can also be seen from Fig. 2 that after loading heparin and BMP2, the coating became more uniform, complete, and compact, which could be helpful to improve the corrosion resistance.

The electrochemical corrosion behaviors of the different samples were further examined by EIS, and the Nyquist curves are shown in Fig. 4b. In order to quantitatively describe the EIS response, the corresponding electrochemical equivalent circuits are constructed and shown in Fig. $4 \mathrm{~b} 1$ (for $\mathrm{Mg}, \mathrm{Mg}-\mathrm{OH}$, and $\mathrm{Mg}-16$ ) and Fig. $4 \mathrm{~b} 2$ (for Mg-GOCS and Mg-Hep/BMP2). The EIS curves were fitted with the corresponding electrochemical equivalent circuits, and the fitting parameters are shown in Table 3. It can be seen from Fig. $4 \mathrm{~b}$ that the shape of the Nyquist diagrams of all samples was similar in the high-frequency regions, which was a capacitive loop in the shape of a semicircle attributed to charge transfer, however, the size of the semicircle was different. As shown in Table 3, it was obvious that there was no significant difference in the values of the solution resistance $\left(R_{S}\right)$ for all samples. $\mathrm{Mg}, \mathrm{Mg}-\mathrm{OH}$, and $\mathrm{Mg}-16$ had only one high-frequency capacitive ring, which can be attributed to charge transfer effect. The increasing size of the capacitive ring after the surface modification indicated that the charge transfer through the double electric layer became more difficult, leading to the increase of the charge transfer resistance $\left(R_{1}\right)$. After GOCS was immobilized on the magnesium alloy surface, apart from the increasing size of the high-frequency capacitance ring, the low-frequency capacitance ring can be detected. The low-frequency capacitance ring is related to the mass transfer and diffusion of $\mathrm{Mg}^{2+}$ caused by corrosion dissolution [41, 42]. The larger size of the low-frequency capacitance ring generally indicates that it is more difficult for metal ions to pass through the surface coating. The occurrence of low-frequency capacitance ring on Mg-GOCS suggested that GOCS layer can prevent the 
Table 3 The EIS fitting parameters of the different samples

\begin{tabular}{lllllllll}
\hline Samples & $R_{s} /\left(\Omega \mathrm{cm}^{2}\right)$ & $Q_{1} /\left(\mu \mathrm{F} \mathrm{cm}^{-2}\right)$ & $n_{1}$ & $R_{1} /\left(\Omega \mathrm{cm}^{2}\right)$ & $\left.Q_{2} /(\mu \mathrm{F} \mathrm{cm})^{-2}\right)$ & $n_{2}$ & $R_{2} /\left(\Omega \mathrm{cm}^{2}\right)$ & $R_{p} /\left(\Omega \mathrm{cm}^{2}\right)$ \\
\hline Mg & 38.24 & $3.529 \times 10^{-6}$ & 0.8964 & 1467 & - & - & - & 1467 \\
Mg-OH & 37.95 & $3.338 \times 10^{-6}$ & 0.8867 & 1902 & - & - & - & 1902 \\
Mg-16 & 38.16 & $5.463 \times 10^{-7}$ & 0.9024 & 2386 & - & - & - & 2386 \\
Mg-GOCS & 38.22 & $5.008 \times 10^{-7}$ & 0.8631 & 3204 & $7.581 \times 10^{-6}$ & 0.9206 & 54 & 3258 \\
Mg-Hep/BMP2 & 38.31 & $3.542 \times 10^{-7}$ & 0.8752 & 3654 & $4.526 \times 10^{-6}$ & 0.8867 & 121 \\
\hline
\end{tabular}

$R_{s}$ solution resistance, $Q_{l}$ double layer capacitive constant phase element, $R_{l}$ charge transfer resistance, $Q_{2}$ coating constant phase element, $R_{2}$ coating resistance, $R_{p}$ polarization resistance, $n_{1}$ and $n_{2}$ correlation coefficient

diffusion of $\mathrm{Mg}^{2+}$, resulting in the improvement of the corrosion resistance. Loading heparin and BMP2 on MgGOCS resulted in the thicker and more uniform coating, therefore the high-frequency capacitance ring of $\mathrm{Mg}-\mathrm{Hep} /$ BMP2 was further increased and it was the largest one among all samples. As compared to Mg-GOCS, the coating resistance $\left(R_{2}\right)$ of $\mathrm{Mg}-\mathrm{Hep} / \mathrm{BMP} 2$ was significantly higher than that of Mg-GOCS, indicating that its corrosion resistance was the best. From the EIS fitting parameters shown in Table 3, it can be seen that the polarization impedance of $\mathrm{Mg}$ was only $1467 \Omega \mathrm{cm}^{2}$, and the value was the lowest among all samples, showing the poor corrosion resistance. Alkali heat treatment and surface immobilization of 16phosphonyl-hexadecanoic acid can effectively improve the corrosion resistance, so the polarization impedance increased. After the bioactive coating was prepared, the polarization impedance further increased, and the impedance value of $\mathrm{Mg}-\mathrm{Hep} / \mathrm{BMP} 2$ reached $3775 \Omega \mathrm{cm}^{2}$, demonstrating that the coating can significantly improve the corrosion resistance. It was considered that the coating was stable in alkaline environment and can effectively prevent the adsorption of corrosive anions.

The degradation rate of the magnesium alloy in the early stage of the implantation plays a key role in the initial surrounding tissue reaction. If the initial degradation rate is too rapid, osteolysis may occur, leading to the inferior bone tissue regeneration [43]. According to the corrosion mechanism of magnesium alloy, its corrosion degradation in physiological environment will produce hydrogen and hydroxide, resulting in the increase of $\mathrm{pH}$ value and the accumulation of $\mathrm{Mg}^{2+}$ [44]. Therefore, the degradation behaviors were investigated by measuring the $\mathrm{pH}$ changes and $\mathrm{Mg}^{2+}$ release behaviors of the different samples immersed in SBF solution. The results are shown in Fig. 4c, d. It can be seen that the blank magnesium alloy made the $\mathrm{pH}$ value of the solution rise rapidly, and the value arrived 9.69 at 7 days, indicating that the unmodified magnesium alloy had rapid degradation rate. The higher $\mathrm{pH}$ would have the damage to tissue and was not conducive to the cell adhesion and growth on the surface [45]. The corrosion resistance of $\mathrm{Mg}-\mathrm{OH}$ and $\mathrm{Mg}-16$ was improved, therefore their degradation rate in SBF became slower, which was confirmed by the decreased $\mathrm{pH}$ changes. However, the protective film formed on the surface degraded quickly with the extension of immersion time, and thus the $\mathrm{pH}$ value of SBF solution was still very high after 7 days of immersion (9.46 for $\mathrm{Mg}-\mathrm{OH}$ and 9.36 for $\mathrm{Mg}-16$, respectively). The covalent immobilization of GOCS can form a stable and dense film on the magnesium alloy surface, therefore the GOCS coating significantly reduced the effect of degradation. After loading Hep/BMP2, the $\mathrm{pH}$ change of SBF was further reduced, implying that the coating can effectively reduce the degradation rate of the magnesium alloy. The results of $\mathrm{Mg}^{2+}$ release in Fig. $4 \mathrm{~d}$ further showed that the release amount of $\mathrm{Mg}^{2+}$ from the unmodified magnesium alloy was the highest, and the concentration of $\mathrm{Mg}^{2+}$ reached $32.67 \mu \mathrm{g} / \mathrm{mL}$ after 7 days. The following surface modification can gradually reduce $\mathrm{Mg}^{2+}$ release amount. The immobilization of GOCS and loading Hep/BMP2 can further reduce the degradation rate of the magnesium alloy in SBF, and the concentration of $\mathrm{Mg}^{2+}$ was only $16.82 \mu \mathrm{g} / \mathrm{mL}(\mathrm{Mg}$ GOCS) and $13.87 \mu \mathrm{g} / \mathrm{mL}$ (Mg-Hep/BMP2) after 7 days, respectively, indicating the decreased corrosion rate.

\subsection{Anticoagulation}

It has been reported that the poor blood compatibility of the bone implant will cause the formation of thrombus, leading to poor blood flow at the implantation site [13], further resulting in local tissue necrosis and even implantation failure. Therefore, the anticoagulation of the different samples was investigated, and the results are shown in Fig. 5. It can be seen that a large number of platelets can be found on Mg surface (Fig. 5b), and the attached platelets displayed the state of aggregation and pseudopod spreading (Fig. 5a), implying that the platelets could have been activated. It was considered that the relative hydrophobicity of the magnesium alloy and $\mathrm{Mg}^{2+}$ release contributed to platelet adhesion and aggregation. The hydrophobic surface can promote fibrinogen adsorption and denaturation, which can promote platelet adhesion, aggregation, and activation [46]. At the same time, the activation of the adherent platelets may be enhanced by the released $\mathrm{Mg}^{2+}$, hydrogen, and high 
a
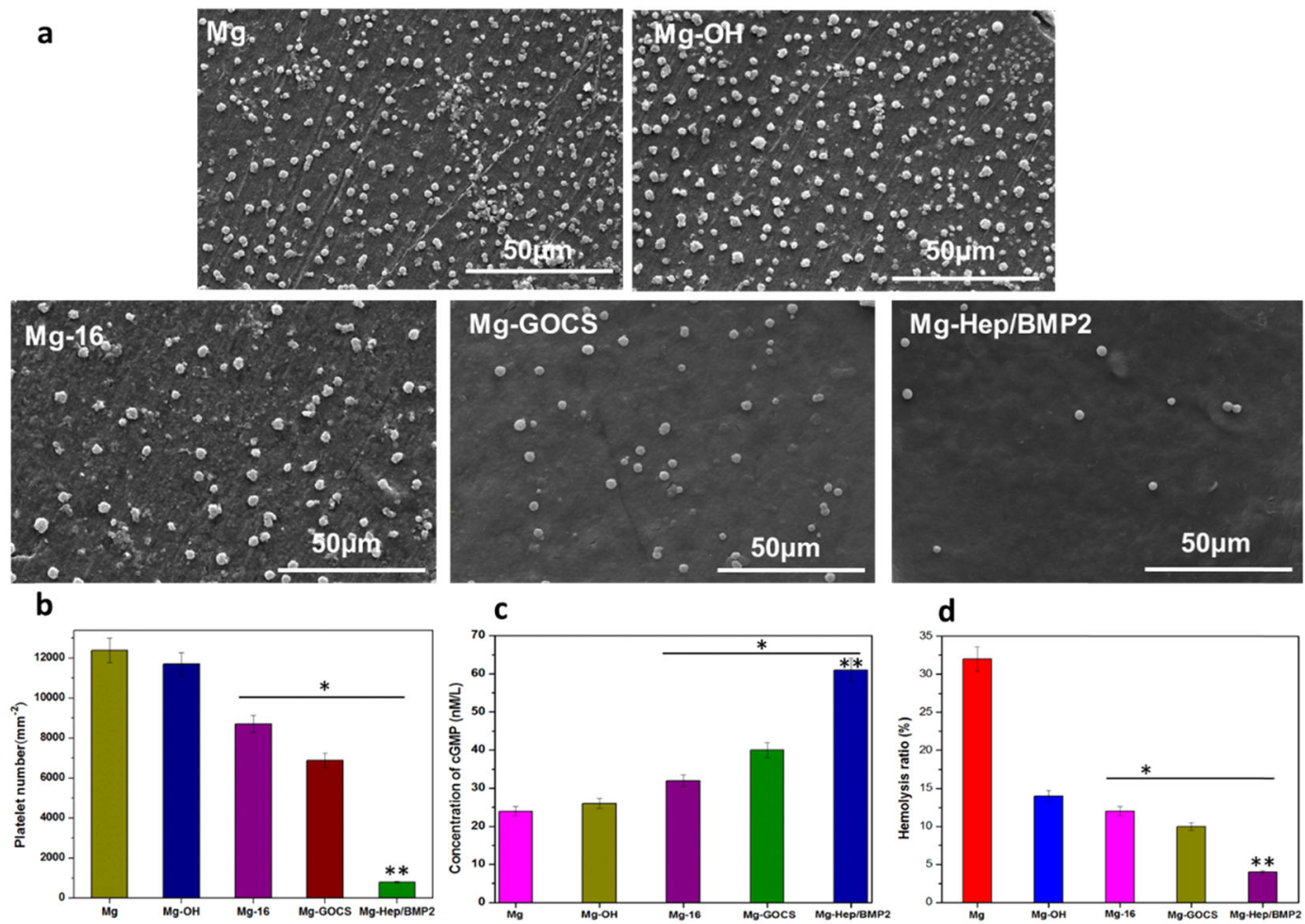

Fig. 5 The representative SEM images (a) and the number (b) of the platelets on the different surfaces. c, d shows the expression concentration of cGMP in platelets, and the hemolysis rate of the different

samples, respectively. For $\mathbf{b}-\mathbf{d}$, statistically differences are indicated by $* p<0.05$ compared with the $\mathrm{Mg}$ and $\mathrm{Mg}-\mathrm{OH}$ group, and $* * p<0.05$ compared with all other groups

$\mathrm{pH}$ value [47], consequently, the adherent platelets on $\mathrm{Mg}$ surface expressed less cGMP (only $24 \mathrm{nM} / \mathrm{L}$ ) and exhibited severely activated state (Fig. 5c). Alkali heat treatment improved the surface wettability and corrosion resistance of the magnesium alloy, which was conducive to reduce the nonspecific protein adsorption and platelet adhesion to a certain extent. However, the number of the attached platelets was still large, and the release of cGMP $(26 \mathrm{nM} / \mathrm{L})$ was enhanced slightly. The platelet number on $\mathrm{Mg}-16$ decreased to 8697 platelets $/ \mathrm{mm}^{2}$, concurrently cGMP expression was increased to $32 \mathrm{nM} / \mathrm{L}$, indicating that it had an effective inhibitory effect on platelet adhesion and activation. On one hand, the improvement of corrosion resistance can reduce $\mathrm{Mg}^{2+}$ release and the change of $\mathrm{pH}$ value, which contributed to maintain the normal physiological environment of the blood. On the other hand, the hydrophilic carboxylic acid groups and the extended carbon chain structure were beneficial for improving the anticoagulation. Although chitosan can promote blood coagulation in some cases, the anticoagulation of the magnesium alloy was further improved after the introduction of GOCS because the number of platelet adhesion and activation was further reduced, which may be due to the fact that the excellent corrosion resistance of GOCS-modified surface can significantly reduce the stimulation and destructive effects of corrosion products on platelets. In addition, GO can also enhance the anticoagulation to some degree [20]. Heparin has excellent blood compatibility, therefore grafting or loading heparin on the surface can significantly reduce the platelet adhesion and activation [48, 49]. After loading Hep/ BMP2 on Mg-GOCS, the number of platelets decreased significantly (only 796 platelets $/ \mathrm{mm}^{2}$ ), moreover, no platelet aggregation was observed and the adhered platelets displayed the typical round shape. The concentration of cGMP reached $61 \mathrm{nM} / \mathrm{L}$, indicating that the modified surface had good antiplatelet adhesion and activation ability.

In order to quantitatively detect the damage degree of the different samples to red blood cells, the hemolysis rates of the different samples were measured, and the results are shown in Fig. 5d. It can be clearly seen that the hemolysis rate of $\mathrm{Mg}$ was $32 \%$, representing a serious hemolysis tendency and poor blood compatibility. $\mathrm{Mg}$ can be easily eroded by $\mathrm{Cl}^{-}$in the physiological environment to release a large amount of $\mathrm{Mg}^{2+}$ and increase $\mathrm{pH}$ value, leading to the fusion between red blood cells and $\mathrm{Ca}^{2+}$ in solution [50], finally resulting in severe hemolysis phenomenon. As compared to the pristine magnesium alloy, $\mathrm{Mg}-\mathrm{OH}$ and $\mathrm{Mg}$ 16 can effectively reduce the influences of $\mathrm{pH}$ value rise and $\mathrm{Mg}^{2+}$ release on red blood cells, leading to an obvious decrease of hemolysis rate. After the introduction of GOCS, the hemolysis rate further decreased. However, the hemolysis rate of Mg-GOCS was still higher than 5\%. Heparin is 
Fig. 6 Fluorescence images of the osteoblast cells cultured on the different magnesium alloys for 1 and 3 days, respectively (green: cytoplasm; blue: nucleus) (color figure online)
Fig. 7 a CCK-8 values of osteoblast cells cultured on the different samples for 1 and 3 days, respectively. ALP (b), OCN (c) expression and mineralization (d) of the osteoblast cells on the different samples. Statistically differences are indicated by $* p<0.05$ compared with the $\mathrm{Mg}$ group, and $\mathrm{Mg}-\mathrm{Hep} / \mathrm{BMP} 2$ has statistically difference $(p<0.05)$ compared other groups

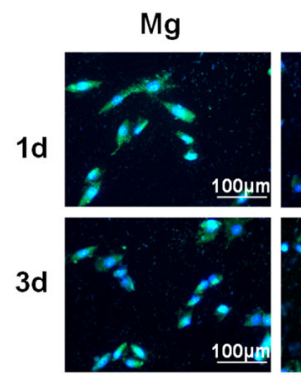

$\mathrm{Mg}-\mathrm{OH}$
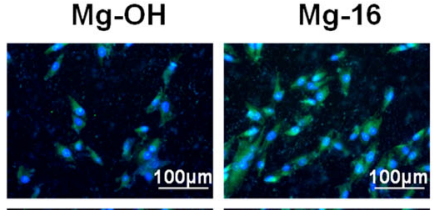

Mg-GOCS

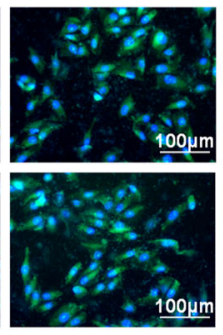

Mg-Hep/BMP2
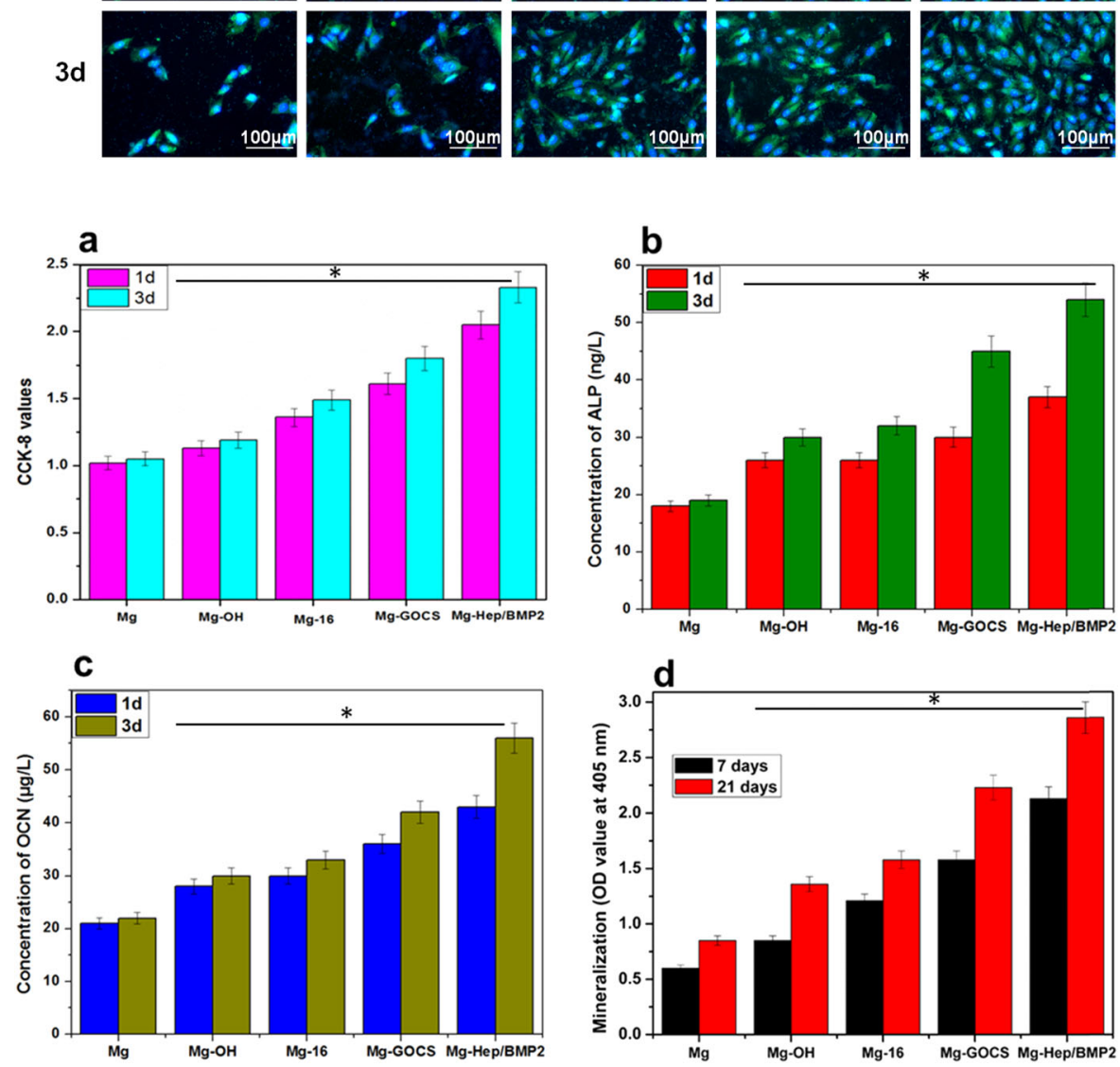

a blood-friendly polysaccharide that can bind to $\mathrm{Ca}^{2+}$ to reduce erythrocyte damage, the hemolysis rate of $\mathrm{Mg}-\mathrm{Hep} /$ BMP2 was reduced to less than $5 \%$, which can meet the requirement of standard of ISO 10994-4:2002 and is acceptable for blood-contacting materials.

\subsection{Osteoblast growth behaviors and function expression}

Figure 6 shows the fluorescent images of the osteoblasts attached on the different surfaces. It can be seen that the number of cells attached on Mg surface was less, which may be due to the fact that a large number of hydrogen bubbles caused by rapid degradation could prevent cell adhesion [51]. At the same time, the higher $\mathrm{pH}$ value of the culture medium also seriously reduced the biological activities of osteoblasts. Therefore, in order to provide a good environment for cell growth, improving the corrosion resistance of magnesium alloy is an important prerequisite. Alkali heat treatment can improve the corrosion resistance to a certain extent, but the protective layer is easy to be dissolved by $\mathrm{Cl}^{-}$, so the number of cell adhesion on $\mathrm{Mg}-\mathrm{OH}$ surface was only slightly more than that of $\mathrm{Mg}$. The corrosion resistance of $\mathrm{Mg}-16$ was better than $\mathrm{Mg}-\mathrm{OH}$, therefore the damage to cells was less and the number of cells on Mg-16 surface was increased. Chitosan is a kind of positively charged polysaccharide, which can interact with negatively charged osteoblasts through electrostatic force and thus promote cell adhesion and growth [52]. The graft of GOCS not only endowed the magnesium alloy surface with positively charged characteristics, but also can significantly improve its corrosion resistance, therefore more osteoblasts with favorable spreading and elongated filopodia can be observed on Mg-GOCS surface. BMP2 can promote the adhesion and proliferation of osteoblasts and promote the expression of osteogenic factor VEGF [53]. Meanwhile, as shown in Fig. 2, loading the complex of heparin and BMP2 on Mg-GOCS can create a uniform surface, therefore, $\mathrm{Mg}-\mathrm{Hep} / \mathrm{BMP} 2$ can significantly promote the osteoblast growth.

The osteoblast proliferation was evaluated by CCK-8 assay, and the results are shown in Fig. 7a. The CCK-8 value of cells on the blank magnesium alloy was the lowest 
among all samples, moreover, there was no significant difference between 1 and 3 days, indicating that osteoblasts could hardly proliferate on the pristine magnesium surface with the extension of the culture time. $\mathrm{Mg}-\mathrm{OH}$ can reduce the effect of the rapid degradation on cell behaviors and thus the CCK-8 value of $\mathrm{Mg}-\mathrm{OH}$ increased slightly. The immobilization of 16-phosphonyl-hexadecanoic acid can further reduce the $\mathrm{pH}$ rise and $\mathrm{Mg}^{2+}$ release, which contributed to the adhesion and proliferation of cells, therefore the CCK- 8 value of cells on Mg-16 increased, and the value of 3 days was significantly higher than that of 1 day, suggesting that the self-assembly of 16-phosphonylhexadecanoic acid can promote cell proliferation. It has been confirmed that both GO and chitosan can promote osteoblast proliferation [54, 55], meanwhile, Mg-GOCS had the excellent corrosion resistance, therefore the CCK- 8 value of cells on Mg-GOCS surface further increased. After loading Hep/BMP2, the enhancement of corrosion resistance can effectively avoid locally high $\mathrm{pH}$ values and $\mathrm{Mg}^{2+}$ concentrations, both of which are known to denature membrane proteins and alter membrane osmotic pressure, thereby disabling membrane channel-dependent signal transport and cell adhesion. Consequently, the CCK-8 values increased significantly for Mg-Hep/BMP2, suggesting that osteoblasts could proliferate well on the surface.

ALP is a marker of early differentiation of osteoblasts and has an important effect on osteoblast mineralization [56], therefore ALP expression in osteoblasts directly reflects the differentiation state of osteoblasts. As shown in Fig. 7b, there was no significant difference in the ALP content on the blank magnesium alloy surface when cultured for 1 and 3 days, respectively. $\mathrm{Mg}-\mathrm{OH}$ and $\mathrm{Mg}-16$ can reduce the effect of rapid degradation on osteoblasts, and provide a hydrophilic environment which was favorable to cell growth and differentiation, therefore the ALP content of cells increased to some degree. As shown in EIS results, MgGOCS not only can increase charge transfer impedance but also had a coating resistance, which can significantly retard the effects of $\mathrm{Mg}^{2+}$ and rapid $\mathrm{pH}$ rise on cell differentiation and thus promote ALP expression. At the same time, GOCS had good biocompatibility and can promote cell adhesion and proliferation, so the ALP of osteoblast on Mg-GOCS increased significantly and the value reached $45 \mathrm{ng} / \mathrm{L}$ after 3 days. BMP2 can stimulate Runx 2 expression and play a pivotal role in the osteoblast differentiation [57]. After loading heparin/BMP2 on the surface, the ALP expression in osteoblasts increased significantly, and the amount was $37 \mathrm{ng} / \mathrm{L}$ for 1 day and $54 \mathrm{ng} / \mathrm{L}$ for 3 days, respectively.

OCN, also known as bone R-hydroxy glutamate protein, is mainly synthesized by osteoblasts, and some by proliferative chondrocytes, which plays an important role in regulating bone calcium metabolism $[58,59]$. The detection of OCN content in cell culture medium represents one of the important methods to investigate the osteoblast functional expression. As shown in Fig. 7c, the OCN content for Mg was relatively low, and the values were $21 \mu \mathrm{g} / \mathrm{L}$ at 1 day and $22 \mu \mathrm{g} / \mathrm{L}$ at 3 days, respectively, it can be attributed to the effect of the limited cell proliferation and the $\mathrm{Mg}^{2+}$ release by the rapid degradation. The OCN expression of osteoblasts on $\mathrm{Mg}-\mathrm{OH}$ and $\mathrm{Mg}-16$ surfaces was not significantly different, but the values were significantly higher than that of the unmodified magnesium alloy, indicating that the enhancement of the corrosion resistance was beneficial to the functional expression of osteoblasts. After grafting GOCS, the expression of OCN in osteoblasts further increased due to the bioactivities of GO and chitosan. It was worth noting that $\mathrm{OCN}$ expression on $\mathrm{Mg}$ Hep/BMP2 surface was the highest among all samples, and the value reached $56 \mu \mathrm{g} / \mathrm{L}$ at 3 days. BMP2 can enhance the bone formation by promoting the osteoblast differentiation from the mesenchymal stem cells and by helping in the biosynthesis of the bone matrix through control of essential factors during osteo-induction to regenerate osseous tissue [60], consequently, loading the complex of heparin and BMP2 on Mg-GOCS surface can significantly promote OCN expression.

ECM protein mineralization is the final stage of osteoblast differentiation. Figure $7 \mathrm{~d}$ shows the mineralization behavior of osteoblasts cultured on the different surfaces for 7 and 21 days, respectively. It can be seen that all samples had a certain function of promoting cell mineralization. With the extension of culture time, better cell mineralization can be achieved. Compared with the unmodified magnesium alloy, the modified magnesium alloy had better hydrophilicity and corrosion resistance as well as good bioactivities, which was conducive to cell adhesion and growth, thus promote the mineralization of cells in varying degrees. In particular, the mineralization of cells was significantly improved after heparin and BMP2 were loaded on the surface.

\section{Conclusion}

The complex of heparin and BMP2 was successfully loaded on the magnesium alloy surface after the immobilization of GOCS on 16-phosphonyl-hexadecanoic acid modified magnesium alloy surface, and a multifunctional bioactive coating was achieved. The surface coating can not only significantly increase the surface wettability, but also effectively enhance the corrosion resistance and reduce degradation rate in simulated physiological environment. Furthermore, the coating can effectively reduce the adhesion and activation of platelets, minimize the hemolysis rate of the magnesium alloy, and therefore significantly improve the anticoagulation. Due to the good cytocompatibility of GOCS and the osteogenic effect of BMP2, the coating can not only significantly promote the adhesion and proliferation of osteoblasts, but also obviously upregulate ALP and OCN expression and promote osteoblast 
mineralization. Therefore, the method of the present study provides a new strategy for surface modification of the magnesium alloy to simultaneously improve the corrosion resistance, blood compatibility, and osseointegration of magnesium alloy; it may expand the application of magnesium alloy in the bone implants.

Acknowledgements We acknowledge the financial supports from the National Natural Science Foundation of China (31870952), Natural Science Foundation of Jiangsu Province of China (BK20181480), the Qinglan Projects of Jiangsu Province of China (2018), and the Key Program for Natural Science Foundation of Jiangsu Higher Education Institutions of China (17KJA530002).

\section{Compliance with ethical standards}

Conflict of interest The authors declare that they have no conflict of interest.

Publisher's note Springer Nature remains neutral with regard to jurisdictional claims in published maps and institutional affiliations.

Open Access This article is licensed under a Creative Commons Attribution 4.0 International License, which permits use, sharing, adaptation, distribution and reproduction in any medium or format, as long as you give appropriate credit to the original author(s) and the source, provide a link to the Creative Commons license, and indicate if changes were made. The images or other third party material in this article are included in the article's Creative Commons license, unless indicated otherwise in a credit line to the material. If material is not included in the article's Creative Commons license and your intended use is not permitted by statutory regulation or exceeds the permitted use, you will need to obtain permission directly from the copyright holder. To view a copy of this license, visit http://creativecommons. org/licenses/by/4.0/.

\section{References}

1. Kamrani S, Fleck C. Biodegradable magnesium alloys as temporary orthopaedic implants: a review. Biometals. 2019;32:183-93.

2. Staiger MP, Pietak AM, Huadmai J, Dias G. Magnesium and its alloys as orthopedic biomaterials: a review. Biomaterials. 2006;27:1728-34.

3. Agarwal S, Curtin J, Duffy B, Jaiswal S. Biodegradable magnesium alloys for orthopaedic applications: a review on corrosion, biocompatibility and surface modifications. Mater Sci Eng C. 2016;68:948-63.

4. Ali M, Hussein MA, Al-Aqeeli N. Magnesium-based composites and alloys for medical applications: a review of mechanical and corrosion properties. J Alloy Compd. 2019;792:1162-90.

5. Shahin M, Munir K, Wen C, Li Y. Magnesium matrix nanocomposites for orthopedic applications: a review from mechanical, corrosion, and biological perspectives. Acta Biomater. 2019;96:1-19.

6. Hung CC, Chaya A, Liu K, Verdelis K, Sfeir C. The role of magnesium ions in bone regeneration involves the canonical Wnt signaling pathway. Acta Biomater. 2019;98:246-55.

7. Yan Y, Wei Y, Yang R, Xia L, Zhao C, Gao B, et al. Enhanced osteogenic differentiation of bone mesenchymal stem cells on magnesium-incorporated titania nanotube arrays. Colloids Surf B. 2019;179:309-16.
8. Shen X, Zhang Y, Ma P, Sutrisno L, Luo Z, Hu Y, et al. Fabrication of magnesium/zinc-metal organic framework on titanium implants to inhibit bacterial infection and promote bone regeneration. Biomaterials. 2019;212:1-16.

9. Tang J, Wang J, Xie X, Zhang P, Lai Y, Li Y, et al. Surface coating reduces degradation rate of magnesium alloy developed for orthopaedic applications. J Orthop Transl. 2013;1:41-8.

10. Wu YF, Wang YM, Jing YB, Zhuang JP, Yan JL, Shao ZK, et al. In vivo study of microarc oxidation coated biodegradable magnesium plate to heal bone fracture defect of $3 \mathrm{~mm}$ width. Colloids Surf B. 2017;158:147-56.

11. Pan C, Hu Y, Hou Y, Liu T, Lin Y, Ye W, et al. Corrosion resistance and biocompatibility of magnesium alloy modified by alkali heating treatment followed by the immobilization of poly (ethylene glycol), fibronectin and heparin. Mater Sci Eng C. 2017;70:438-49.

12. Wan P, Tan L, Yang K. Surface modification on biodegradable magnesium alloys as orthopedic implant materials to improve the bio-adaptability: a review. J Mater Sci Technol. 2016;32:827-34.

13. Yu X, Liu L, Xie Z, Dong C, Zhao L, Zhang J, et al. Bone marrow versus peripheral blood as a graft source for haploidentical donor transplantation in adults using post-transplant cyclophosphamide - a systematic review and meta-analysis. Crit Rev Oncol Hematol. 2019;133:120-8.

14. Singh DP, Herrera CE, Singh B, Singh S, Singh RK, Kumar R. Graphene oxide: an efficient material and recent approach for biotechnological and biomedical applications. Mater Sci Eng C. 2018;86:173-97.

15. Xie H, Cao T, Rodríguez-Lozano FJ, Luong-Van EK, Rosa V. Graphene for the development of the next-generation of biocomposites for dental and medical applications. Dent Mater. 2017;33:765-74.

16. Qiu Z, Wang E, Wu J, Zhang Y, Qu Y, Wu X. Graphene oxide as a corrosion-inhibitive coating on magnesium alloys. RSC Adv. 2015;55:44149-59.

17. Tong LB, Zhang JB, Xu C, Wang X, Song SY, Jiang ZH, et al. Enhanced corrosion and wear resistances by graphene oxide coating on the surface of $\mathrm{Mg}-\mathrm{Zn}-\mathrm{Ca}$ alloy. Carbon. 2016; 109:340-51.

18. Catt K, Li H, Cui T. Poly (3,4-ethylenedioxythiophene) graphene oxide composite coatings for controlling magnesium implant corrosion. Acta Biomater. 2017;58:530-40.

19. Chen HQ, Müller MB, Gilmore KJ, Wallace GG, Li D. Mechanically strong, electrically conductive, and biocompatible graphene paper. Adv Mater. 2008;20:3557-61.

20. Pan CJ, Pang LQ, Gao F, Wang YN, Liu T, Ye W, et al. Anticoagulation and endothelial cell behaviors of heparin-loaded graphene oxide coating on titanium surface. Mater Sci Eng C. 2016;63:333-40.

21. Shin SR, Li YC, Jang HL, Khoshakhlagh P, Akbari M, Nasajpour A, et al. Graphene-based materials for tissue engineering. Adv Drug Deliv Rev. 2016;105:255-74.

22. Zhao J, Chen LJ, Yu K, Chen C, Dai YL, Qiao XY, et al. Effects of chitosan coating on biocompatibility of $\mathrm{Mg}-6 \% \mathrm{Zn}-10 \% \mathrm{Ca}_{3}(\mathrm{PO} 4)_{2}$ implant. Trans Nonferrous Met Soc China. 2015;25:824-31.

23. Kim SE, Kim CS, Yun YP, Yang DH, Park K, Kim SE, et al. Improving osteoblast functions and bone formation upon BMP-2 immobilization on titanium modified with heparin. Carbohydr Polym. 2014;114:123-32.

24. Xu K, Cai K. Self-assembled phase-transited lysozyme/heparin coating on titanium surfaces for improved hemocompatibility. Mater Lett. 2019;247:95-8.

25. Rawadi G, Vayssière B, Dunn F, Baron R, Roman-Roman S. BMP-2 controls alkaline phosphatase expression and osteoblast mineralization by a Wnt autocrine loop. J Bone Min Res. 2003;18:1842-53. 
26. Ji X, Chen D, Xu C, Harris SE, Mundy GR, Yoneda T. Patterns of gene expression associated with BMP-2-induced osteoblast and adipocyte differentiation of mesenchymal progenitor cell 3T3F442A. J Bone Min Metab. 2000;18:132-9.

27. Annamalai RT, Turner PA, Carson WF IV, Levi B, Kunkel S, Stegemann JP. Harnessing macrophage-mediated degradation of gelatin microspheres for spatiotemporal control of BMP2 release. Biomaterials. 2018;161:216-27.

28. Pan CJ, Tang JJ, Weng YJ, Wang J, Huang N. Preparation and in vitro release profiles of drug-eluting controlled biodegradable polymer coating stents. Colloids Surf B. 2009;73:199-206.

29. Gao F, Hu Y, Li G, Liu S, Quan L, Yang Z, et al. Layer-by-layer deposition of bioactive layers on magnesium alloy stent materials to improve corrosion resistance and biocompatibility. Bioact Mater. 2020;5:611-23.

30. Fan Y, Zhang Y, Zhao Q, Xie Y, Luo R, Yang P, et al. Immobilization of nano $\mathrm{Cu}-\mathrm{MOFs}$ with polydopamine coating for adaptable gasotransmitter generation and copper ion delivery on cardiovascular stents. Biomaterials. 2019;204:36-45.

31. Pan C, Hou Y, Zhang B, Dong Y, Ding H. Blood compatibility and interaction with endothelial cells of titanium modified by sequential immobilization of poly (ethylene glycol) and heparin. J Mater Chem B. 2014;2:892-902.

32. Shen XK, Hu Y, Xu GQ, Chen WZ, Xu K, Ran QC, et al. Regulation of the biological functions of osteoblasts and bone formation by $\mathrm{Zn}$-incorporated coating on microrough titanium. ACS Appl Mater Interfaces. 2014;6:16426-40.

33. Chang L, Cao F, Cai J, Liu W, Zhang J, Cao C. Formation and transformation of $\mathrm{Mg}(\mathrm{OH}) 2$ in anodic coating using FTIR mapping. Electrochem Commun. 2009;11:2245-48.

34. Ho YC, Mi FL, Sung HW, Kuo PL. Heparin-functionalized chitosan-alginate scaffolds for controlled release of growth factor. Int J Pharm. 2009;376:69-75.

35. Ho CY, Huang SM, Lee ST, Chang YJ. Evaluation of synthesized graphene oxide as corrosion protection film coating on steel substrate by electrophoretic deposition. Appl Surf Sci. 2019;477:226-31.

36. Zhai XF, Li K, Guan F, Sun CT, Duan JZ, Hou BR. Corrosion behavior of the chitosan-zinc composite films in sulfate-reducing bacteria. Surf Coat Technol. 2018;344:259-68.

37. Pozzo L, da Conceição TF, Spinelli A, Scharnagl N, Pires ATN. Chitosan coatings crosslinked with genipin for corrosion protection of AZ31 magnesium alloy sheets. Carbohyd Polym. 2018;181:71-7.

38. Xie J, Jia H, Fang L, Liao X, Du R, Wu F, et al. Facile fabrication and biological properties of super-hydrophobic coating on magnesium alloy used as potential implant materials. Surf Coat Technol. 2020;384:125223.

39. Zhou M, Yan LC, Ling H, Diao YP, Pang XL, Wang YL, et al. Design and fabrication of enhanced corrosion resistance $\mathrm{Zn}-\mathrm{Al}$ layered double hydroxides films based anion-exchange mechanism on magnesium alloys. Appl Surf Sci. 2017;404:246-53.

40. Wang L, Shinohara T, Zhang BP. Influence of chloride, sulfate and bicarbonate anions on the corrosion behavior of AZ31 magnesium alloy. J Alloy Compd 2010;496:500-7.

41. Liu X, Zhang T, Shao Y, Meng G, Wang F. Effect of alternating voltage treatment on the corrosion resistance of pure magnesium. Corros Sci. 2009;51:1772-9.

42. Rahman ZU, Deen KM, Haider W. Controlling corrosion kinetics of magnesium alloys by electrochemical anodization and investigation of film mechanical properties. Appl Surf Sci. 2019;484:906-16.
43. Zhen $\mathrm{Z}, \mathrm{Xi} \mathrm{TF}$, Zheng YF. A review on in vitro corrosion performance test of biodegradable metallic materials. Trans Nonferrous Met Soc China. 2013;23:2283-93.

44. Chalisgaonkar R. Insight in applications, manufacturing and corrosion behaviour of magnesium and its alloys-a review. Mater Today Proc. 2020;26:1060-71.

45. Hornberger H, Virtanen S, Boccaccini AR. Biomedical coatings on magnesium alloys-a review. Acta Biomater. 2012;8:2442-55.

46. Zhang L, Casey B, Galanakis DK, Marmorat C, Skoog S, Vorvolakos $\mathrm{K}$, et al. The influence of surface chemistry on adsorbed fibrinogen conformation, orientation, fiber formation and platelet adhesion. Acta Biomater. 2017;54:164-74.

47. Gu X, Zheng Y, Cheng Y, Zhong S, Xi T. In vitro corrosion and biocompatibility of binary magnesium alloys. Biomaterials. 2009;30:484-98

48. Li GC, Xu QF, Yang P. Inhibiting smooth muscle cell proliferation via immobilization of heparin/fibronectin complexes on titanium surfaces. Biomed Environ Sci. 2015;28:378-82.

49. Yang $\mathrm{Y}$, Gao $\mathrm{P}$, Wang $\mathrm{J}$, Tu Q, Bai L, Xiong $\mathrm{K}$, et al. Endothelium-mimicking multifunctional coating modified cardiovascular stents via a stepwise metal-catechol-(amine) surface engineering strategy. Research. 2020;2020:9203906.

50. Kang IK, Kwon OH, Lee YM, Yong KS. Preparation and surface characterization of functional group-grafted and heparinimmobilized polyurethanes by plasma glow discharge. Biomaterials. 1996;17:841-7.

51. Kraus T, Fischerauer SF, Hänz AC, Uggowitzer PJ, Löffler JF, Weinber AM. Magnesium alloys for temporary implants in osteosynthesis: in vivo studies of their degradation and interaction with bone. Acta Biomater. 2012;8:1230-8.

52. Foss BL, Ghimire N, Tang R, Sun Y, Deng Y. Bacteria and osteoblast adhesion to chitosan immobilized titanium surface: a race for the surface. Colloids Surf B. 2015;134:370-6.

53. Han L, Lin H, Lu X, Zhi W, Meng KF, Jiang Q. BMP2encapsulated chitosan coatings on functionalized Ti surfaces and their performance in vitro and in vivo. Mater Sci Eng C. 2014;40:1-8.

54. Depan D, Pesacreta TC, Misra RDK. The synergistic effect of a hybrid graphene oxide-chitosan system and biomimetic mineralization on osteoblast functions. Biomater Sci. 2014;2:264-74.

55. Su J, Du Z, Xiao L, Wei F, Yang Y, Li M, et al. Graphene oxide coated titanium surfaces with osteoimmunomodulatory role to enhance osteogenesis. Mater Sci Eng C. 2020;113:110983.

56. Nakamura T, Nakamura-Takahashi A, Kasahara M, Yamaguchi A, Azuma T. Tissue-nonspecific alkaline phosphatase promotes the osteogenic differentiation of osteoprogenitor cells. Biochem Biophys Res Commun. 2020;524:702-9.

57. Phimphilai M, Zhao Z, Boules H, Roca H, Franceschi RT. BMP signaling is required for RUNX2-dependent induction of the osteoblast phenotype. J Bone Min Res. 2006;21:637-46.

58. Kosmidis S, Polyzos A, Harvey L, Youssef M, Denny CA, Dranovsky A, et al. RbAp48 protein is a critical component of GPR158/OCN signaling and ameliorates age-related memory loss. Cell Rep. 2018;25:959-73.

59. Hosseini S, Naderi-Manesh H, Vali H, Eslaminejad MB, Sayahpour FA, Sheibani S, et al. Contribution of osteocalcin-mimetic peptide enhances osteogenic activity and extracellular matrix mineralization of human osteoblast-like cells. Colloids Surf B. 2019;173:662-71.

60. Bessa PC, Casal M, Reis RL. Bone morphogenetic proteins in tissue engineering: the road from the laboratory to the clinic, part I (basic concepts). J Tissue Eng Regen Med. 2008;2:1-13. 